\title{
Rational Design of Donor-Acceptor Based Semiconducting Copolymers with High Dielectric Constants
}

\author{
Published as part of The Journal of Physical Chemistry virtual special issue "D. D. Sarma Festschrift".
}

Aiswarya Abhisek Mohapatra, Yifan Dong, Puttaraju Boregowda, Ashutosh Mohanty, Aditya Sadhanala, Xuechen Jiao, Awadhesh Narayan, Christopher R. McNeill, James R. Durrant,* and Satish Patil*

Cite This: J. Phys. Chem. C 2021, 125, 6886-6896

Read Online

\section{ACCESS | Lلll Metrics \& More | 回 Article Recommendations | S1 Supporting Information}

ABSTRACT: The low dielectric constant of organic semiconductors limits the efficiency of organic solar cells (OSCs). In an attempt to improve the dielectric constant of conjugated polymers, we report the synthesis of three semiconducting copolymers by combining the thiophene-substituted diketopyrrolopyrrole (TDPP) monomer with three different monomeric units with varying electron donating/accepting strengths: benzodithiophene (BBT-3TEGTDPP), TDPP (TDPP-3TEG-TDPP), and naphthalene diimide (P(gNDI-TDPP)). Among the series, BBT-3TEG-TDPP and P(gNDI-TDPP) exhibited the highest dielectric constants $(\sim 5)$ at $1 \mathrm{MHz}$ frequency, signifying the contribution of dipolar polarization from TEG side-chains. Furthermore, transient absorption spectroscopic studies performed on these polymers indicated low exciton diffusion length as observed in common organic semiconducting polymers. Our findings suggest that utilizing the polar side-chains enhances the dielectric constant in a frequency regime of megahertz. However, it is not sufficient to reduce the Coulombic interaction between hole and electron in excitonic solar cells.

\section{INTRODUCTION}

In contrast to inorganic semiconductors, optical excitation of an organic semiconductor leads to the formation of localized Frenkel exciton with significantly large binding energy than room temperature thermal energy $\left(k_{\mathrm{B}} T\right)$. As a result, the photogenerated charge carriers sustain a strong Coulombic interaction, which leads to significant geminate recombination losses in OSCs. ${ }^{1,2}$ In OSCs, a second component with high electron affinity such as fullerene is incorporated into the active layer to surpass the exciton binding energy and establish bulk heterojunction $(\mathrm{BHJ})$ between donor and acceptor. ${ }^{3,4}$ Although, the concept of $\mathrm{BHJ}$ has been continuously evolved and witnessed a record power conversion efficiency (PCE) of $\sim 18 \%$ for single-junction OSCs, the main disadvantage of $\mathrm{BHJ}$ is the morphology domains of donor and acceptor dictate the PCE of the device. ${ }^{5,6}$ The morphology of donor/acceptor blend is sensitive to numerous parameters such as molecular structure of donor and acceptor, processing solvent, annealing temperature of thin film, spin-coating conditions, and solvent additives. $^{7,8}$ To explore the full potential of any newly synthesized polymer donor materials or small molecule acceptor, this ponderous process needs to be optimized. ${ }^{9,10}$ Despite these tedious efforts, phase separation of donor and acceptor domains is not limited to exciton diffusion length due to the inherent thermodynamic instability of the blend. ${ }^{11,12}$ The difference in tendency of crystallization of donor and acceptor drives them to form microscopic domains larger than the exciton diffusion length. ${ }^{13-15}$ These microscopic domains evolve further with the time and lead to spinodal decomposition of the blend, resulting in a shorter lifetime of OSCs. ${ }^{8,12,15}$

It has been observed that many of the high performing blends have $\sim 300 \mathrm{meV}$ energy offset in frontier molecular orbital energy levels which sets up $E_{\mathrm{CT}}<E_{\mathrm{g}}{ }^{16}$ Several experimental studies show that the hybridization of CT states with the excited singlet state and higher $E_{\mathrm{CT}}$ can help reduce the voltage losses. ${ }^{17,18}$ However, recent studies based on nonfullerene acceptor (NFA) based OSCs have shown that the CT states can be efficiently dissociated even with a negligible energy offset. ${ }^{19,20}$ The contribution from entropy and energetic disorder in driving the charge separation efficiently has been established by Hood et al., thus challenging the preconceived notion of hindrance of charge separation by a large thermodynamic barrier. ${ }^{21}$ The low dielectric constant $\left(\varepsilon_{\mathrm{r}}\right)$ of organic semiconductors is pivotal to incur losses due to geminate and nongeminate recombination. ${ }^{22}$ This suggests that increasing dielectric constant of organic semiconductors

Received: January 14, 2021

Revised: $\quad$ March 9, 2021

Published: March 23, 2021 
can help surpass the Coulomb capture radius, resulting in an expected decrease in charge carrier recombination events (Figure 1a). In addition, this would make the complicated BHJ device architecture no longer necessary since the photon absorption will lead to the creation of free charge carriers.

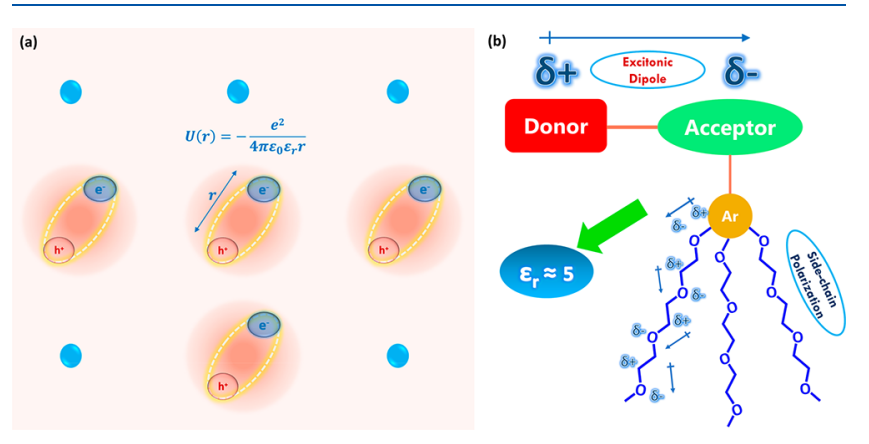

Figure 1. (a) The dotted yellow line represents Frenkel excitons, typically found in organic materials, which are localized at their site of creation unlike the Wannier excitons. This schematic is shown only for demonstration purposes; note that the number of excitons per site is not to be related to real systems. (b) The schematic shows the backbone and side-chain dipolar polarization which enables to achieve a high dielectric constant in the case for organic semiconducting polymers.

Toward this goal, many attempts have been made from a synthesis perspective, but the progress in this regard has been slow. $^{22,23,32-34,24-31}$ In fact, the $\varepsilon_{\mathrm{r}}$ 's of donor and acceptor systems utilized in high-efficiency OSCs are the least explored parameters. Functionally tuning organic molecules to achieve high $\varepsilon_{\mathrm{r}}$ without compromising the solubility, bandgap, ionization potential, electron affinity, and carrier mobilities is synthetically challenging. ${ }^{33}$

The cautious approach in the scientific community to improve the $\varepsilon_{\mathrm{r}}$ has largely focused on side-chain engineering which has a negligible or minimal impact on electronic structure $^{35}$ but significantly influences solid state packing and energetic disorder. ${ }^{36}$ In one of the very first reports, triethylene glycol (TEG) side-chains were introduced by Breselge et al. in a poly( $p$-phenylenevinylene) (PPV) derivative, and $\varepsilon_{\mathrm{r}}$ was enhanced. ${ }^{37}$ When blended with a fullerene derivative in $\mathrm{BHJ}$, charge dissociation in the polymer was enhanced as compared to a less polar PPV derivative. ${ }^{38}$ However, the above-modified polar PPV moiety delivered poorer performance as compared to the less polar one when blended with the fullerene derivative, which was attributed to the unfavorable morphology. ${ }^{37}$ In another report, when nitrile $(-\mathrm{CN})$ functional groups were introduced at the terminal position of butyl or octyl side chains of poly(dithienosilole-thienopyrrolodione), an improved $\varepsilon_{\mathrm{r}}$ was observed. ${ }^{35}$ However, introduction of nitrile groups increased the energetic disorder to the charge transport of the polymers; hence the hole mobility decreased but the electron mobility was enhanced, and the imbalance in charge transport led to inferior photovoltaic performances as compared to their unsubstituted counterparts. In another contrasting and rather encouraging report, the introduction of nitrile groups in the terminal position of alkyl side chains of the electron-deficient diketopyrrolopyrrole (DPP) unit of an indacenodithiophene (IDT) based copolymer improved the $\varepsilon_{\mathrm{r}}$ as compared to the copolymer with alkyl side chain. ${ }^{22}$ The increment in $\varepsilon_{\mathrm{r}}$ reflected in lower exciton binding energy and suppressed nongeminate recombination loss which collectively resulted in improved photovoltaic performance. These results showed that increased $\varepsilon_{\mathrm{r}}$ of photoactive materials in the megahertz frequency range can definitely suppress the nongeminate recombination.

To realize nonexcitonic OSCs, a high dielectric constant of organic materials is not only desirable in the low-frequency (megahertz) but also at the high-frequency (terahertz) limit. ${ }^{32}$ However, increasing $\varepsilon_{\mathrm{r}}$ via side-chain engineering is short-lived and may not be sustained in high-frequency limits (approximately terahertz), corroborating the fact that the enhancement of $\varepsilon_{\mathrm{r}}$ is not electronic but only because of nuclear relaxations. ${ }^{29,32,39}$ The strategy of introduction of OEG based polar side-chains has been shown to enhance the $\varepsilon_{\mathrm{r}}$ of various $\mathrm{DPP}, \mathrm{PPV}$, and fullerene derivatives to more than 5 in the megahertz region without compromising their carrier mobilities and solubility and has laid the foundation of realizing single-component OSCs. Over the years, many such attempts have been made by various researchers by utilizing double cable polymers where donor and acceptor groups are covalently linked to each other. ${ }^{40}$ PCEs ranging from 0.1 to $8.4 \%$ have been achieved with many different double cable polymers and shown a promise to simplify the device fabrication process. ${ }^{40-47}$ This has encouraged the scientific community to develop more such molecules to envisage and understand the role of high $\varepsilon_{\mathrm{r}}$ in these solution-processable nonexcitonic OSCs.

Herein, we report synthesis of DPP-based donor-acceptordonor type $\pi$-conjugated copolymers with benzodithiophene (BDT) and naphthalene diimide (NDI) as comonomers. The properties of these three were compared with 2DPP-OD-TEG, a DPP based copolymer which was reported by our group earlier. ${ }^{33,48-50}$ Two of these polymers show $\varepsilon_{\mathrm{r}} \sim 5$ in the megahertz frequency range which is attributed to the contribution from dipolar polarization of the conjugated backbone. $^{33}$ We further introduced multiple TEG chains with conjugated spacer units in side-chains of two of the polymers to understand the effect of $\mathrm{C}-\mathrm{O}$ bond polarization on $\varepsilon_{\mathrm{r}}$ (Figure $1 \mathrm{~b}$ ). BBT-3TEG-TDPP and TDPP-3TEG-TDPP have different backbones but the same side-chains; however, BBT-3TEG-TDPP exhibits an $\varepsilon_{\mathrm{r}}$ value nearly $50 \%$ higher than that of TDPP-3TEG-TDPP.

Furthermore, we probed the generation, migration, and decay dynamics of excitons in these polymers using transient absorption (TA) spectroscopy. Surprisingly, we did not observe free charge carrier generation in any of these polymers. Although we have observed improved $\varepsilon_{\mathrm{r}}$ in the megahertz frequency range, the exciton dissociation in OSCs occurs in a short time (approximately picoseconds to femtoseconds) scale. This experimental data suggests that the dipolar polarization is dominated by nuclear relaxations of side-chains which fades at higher frequencies. ${ }^{29}$ The TEG side-chains of the polymer possess high dipolar polarizability as evident from the enhanced dielectric constant in the megahertz regime, but as their reorientation is slower than the typical mobility of charge carriers in OPVs, ${ }^{32}$ it is insufficient to surpass the Coulombic attraction to generate free charge carriers as evident from TA spectroscopic studies. The exciton diffusion length and lifetime were found to be the highest for BBT-3TEG-TDPP, which corroborates well with its highest dielectric constant among the four. The lowest structural disorder was observed for BBT3TEG-TDPP as evident from the Urbach energy $\left(E_{\mathrm{U}}\right)$ extracted via photothermal deflection spectroscopy (PDS) data. We hypothesize that the contribution of dipolar 
Scheme 1. Synthesis of Polymers with Suzuki and Stille Coupling Reactions

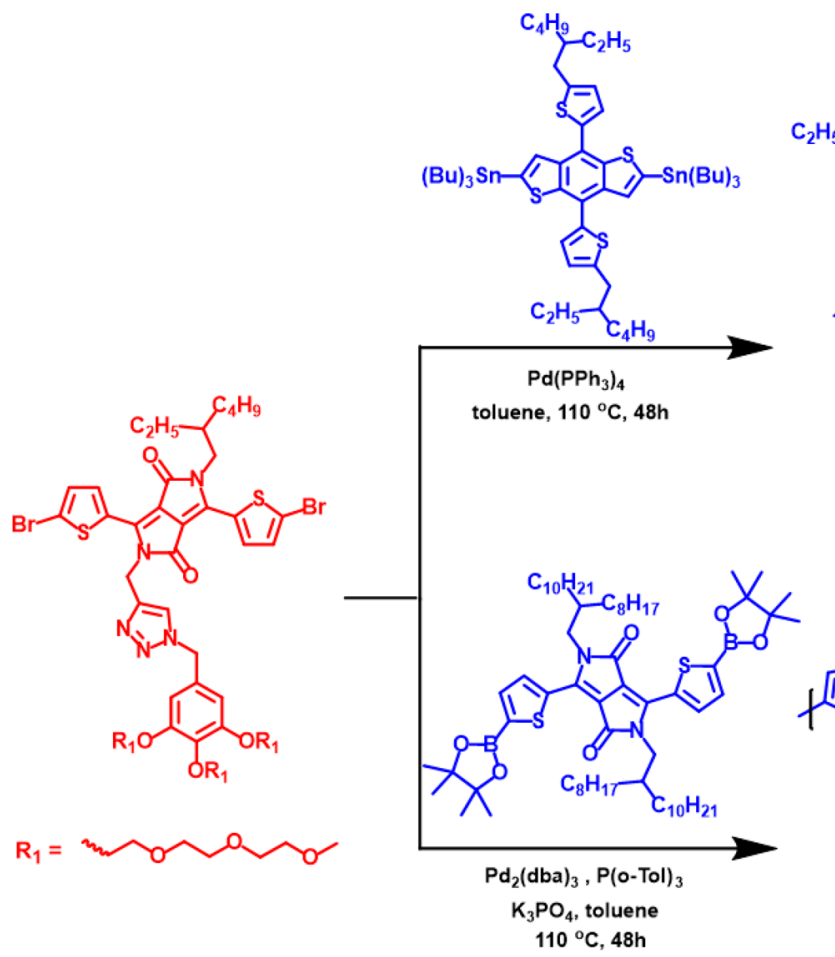

$110^{\circ} \mathrm{C}, 48 \mathrm{~h}$

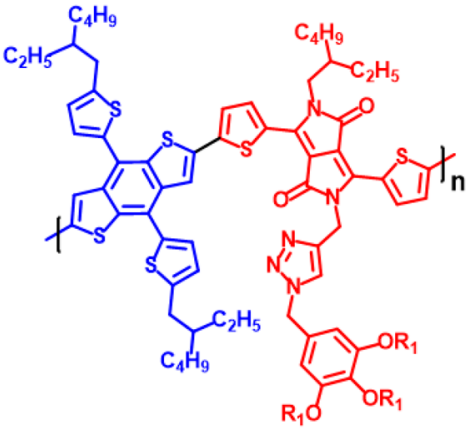

BBT-3TEG-TDPP<smiles>O=C1OC(=O)c2c(Br)cc3c4c(c(Br)cc1c24)C(=O)OC3=O</smiles><smiles>COCCCOCCOCC(=O)O</smiles>

$0-X y l e n e, 16 \mathrm{~h}$ reflux<smiles></smiles>

$\mathrm{R}_{2}$

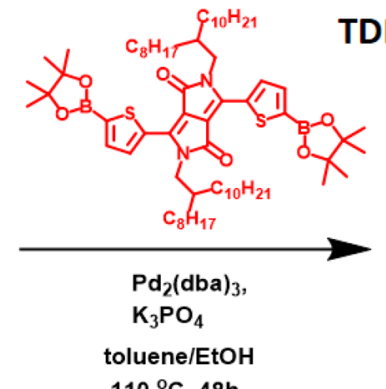

$110^{\circ} \mathrm{C}, 48 \mathrm{~h}$

$$
R_{2}=\text { m }
$$

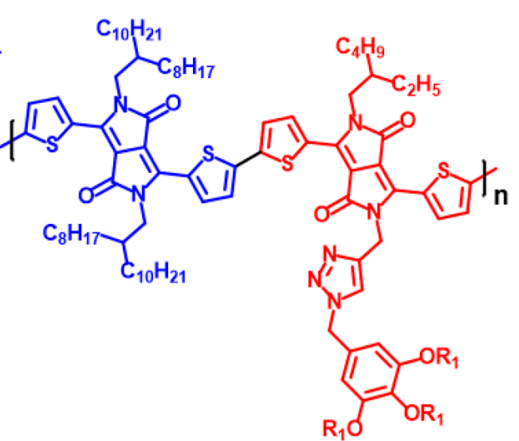

TDPP-3TEG-TDPP

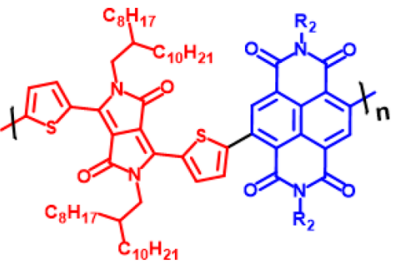

P(gNDI-TDPP)

polarization in the polymeric backbone along with the strength of donors/acceptors plays an important role in achieving higher $\varepsilon_{\mathrm{r}}$ and hence can be utilized to rationally design conjugated polymers with high $\varepsilon_{\mathrm{r}}$. The pertaining question of achieving free charge generation by improving the $\varepsilon_{\mathrm{r}}$ still remains open and is a matter of further investigation.

\section{EXPERIMENTAL SECTION}

Materials. All the chemicals were used as received without any further modification. For synthesis of polymers, all the solvents and reagents were purchased from Sigma-Aldrich and used as received. PEDOT:PSS (Clevios PVP AI 4083) was purchased from Heraeus. Anhydrous 1,1,2,2-tetrachloroethane (TCE) and chloroform were purchased from Sigma-Aldrich. Prepatterned ITO-coated glass substrates $\left(12 \times 12 \times 1.1 \mathrm{~mm}^{3}\right.$ with $7 \mathrm{~mm}$ ITO stripe) were purchased from Colorado Concept Coatings, U.S. Evaporation grade silver was purchased from Sigma-Aldrich. The monomers $\operatorname{TDPP}(\mathrm{BE})_{2}$, 3ETGTDPP-Br $r_{2}, \mathrm{BBT}\left(\mathrm{SnBu}_{3}\right)_{2}$, and NDITEG-Br $\mathrm{B}_{2}$ were synthesized by following procedures reported in the literature. $^{48,51,52}$
Methods. Average molecular weights $\left(M_{w}, M_{\mathrm{n}}\right)$ were determined by gel permeation chromatography (GPC) against polystyrene standards. THF was used as eluent for P(gNDITDPP), and chloroform was used for the other three polymers with a flow rate of $1 \mathrm{~mL} / \mathrm{min}$. Monomers were synthesized according to the reported methods. Thermogravimetric analysis (TGA) measurements were conducted on a Mettler Toledo TGA SDTA 851 apparatus at a heating rate of $10^{\circ} \mathrm{C} /$ min under a nitrogen atmosphere.

Polymer thin films were prepared by spinning their dissolved solutions in a chloroform:TCE $(1: 1)$ mixture $(10 \mathrm{mg} / \mathrm{mL})$ at $1000 \mathrm{rpm}$ on precleaned ozone-treated Spectrosil substrates. UV-vis absorption spectra were recorded in transmission mode by using a PerkinElmer (Lambda 35) spectrometer in ambient conditions. The thickness of active layers was measured by using a Bruker Dektak XT profilometer with a $2 \mu \mathrm{m}$ tip scanning with $2 \mathrm{mg}$ force.

Cyclic voltammetry (CV) measurements were performed by drop-casting polymer thin films from their dissolved solutions on platinum disc electrodes in $\mathrm{CHCl}_{3} \cdot \mathrm{Bu}_{4} \mathrm{NPF}_{6}(0.1 \mathrm{M})$ was used as supporting electrolyte under a nitrogen atmosphere at 
(a)

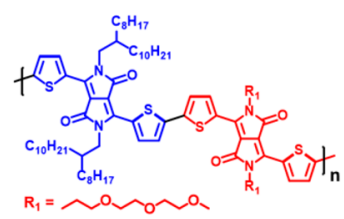

2DPP-OD-TEG

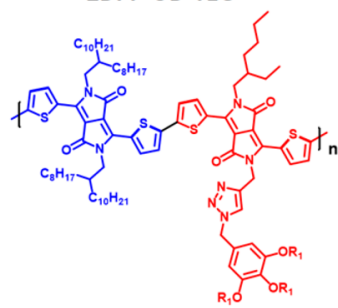

TDPP-3TEG-TDPP

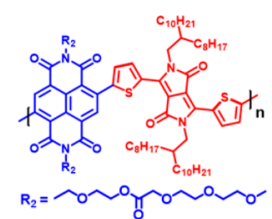

P(gNDI-TDPP)

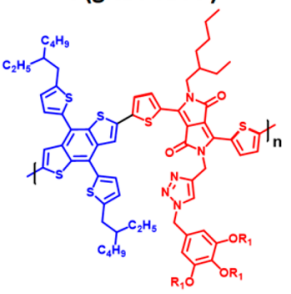

BBT-3TEG-TDPP

(d)
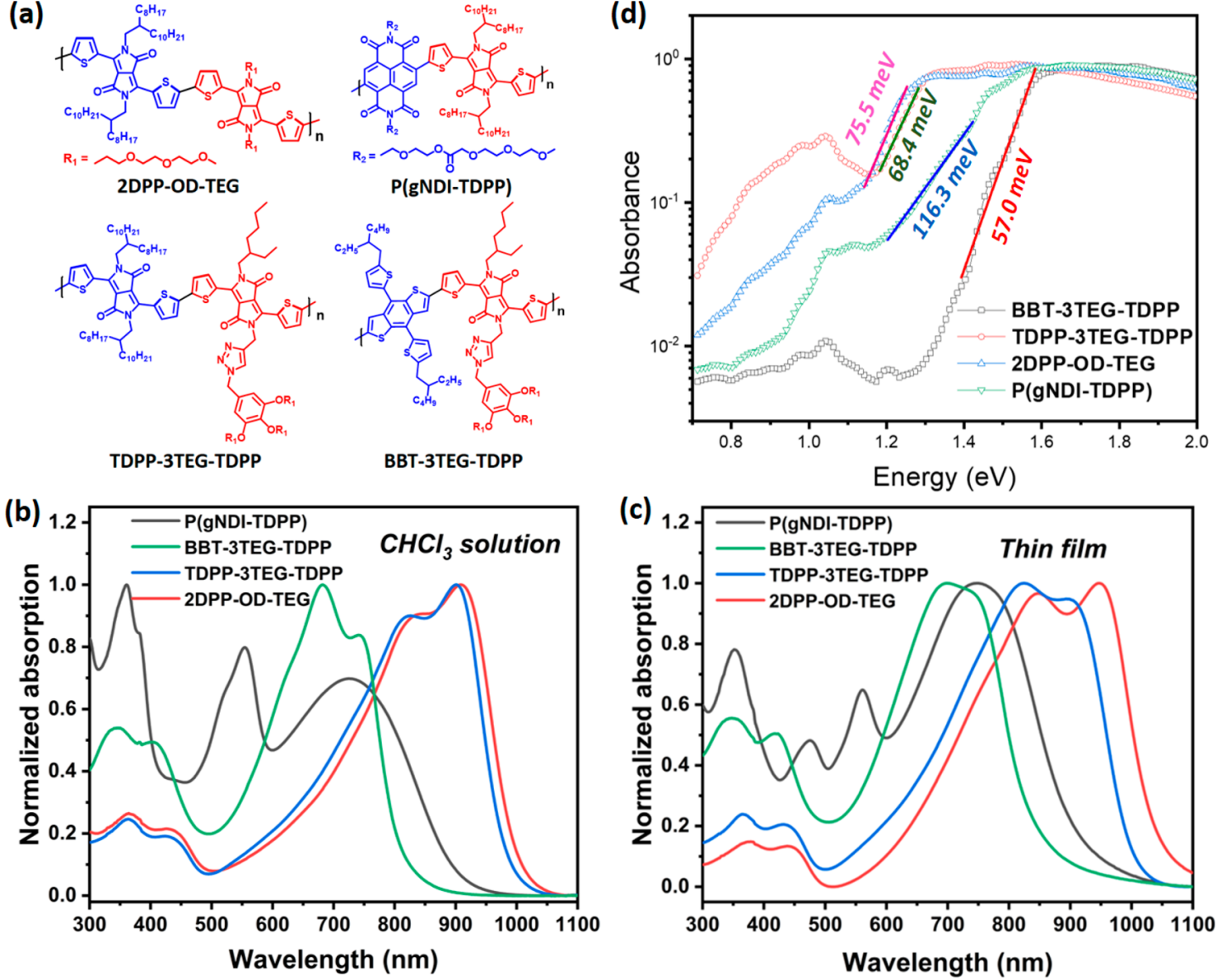

Figure 2. (a) Molecular structures of the synthesized copolymers. UV-vis absorption spectra of polymers in (b) solution phase and in (c) thin film showing extended absorption until $1100 \mathrm{~nm}$ because of solid state intermolecular interactions; among the series 2DPP-OD-TEG has lowest optical bandgap. (d) Photothermal deflection spectra of all the polymers showing tail state absorption; the dark lines show the fitted region of the absorption tail to extract the Urbach energy $\left(E_{\mathrm{U}}\right)$ (shown next to the fitted lines).

room temperature. $\mathrm{Ag} / \mathrm{AgCl}$ was used as the reference electrode where a platinum rod was employed as counter electrode and the ferrocene/ferrocenium $\left(\mathrm{Fc} / \mathrm{Fc}^{+}\right)$couple as the standard.

Devices for impedance spectroscopy measurement were fabricated in ITO/PEDOT:PSS/polymer/Ag architecture. For device fabrication, prepatterned ITO substrates were cleaned by ultrasonic treatment in soap solution, deionized water, acetone, and isopropanol, sequentially, for $15 \mathrm{~min}$ each. Then the substrates were dried with $\mathrm{N}_{2}$ flow, followed by oxygenplasma treatment for $15 \mathrm{~min}$. A thin layer $(\approx 30 \mathrm{~nm})$ of PEDOT:PSS was prepared by spin-coating at $5000 \mathrm{rpm}$ for 45 $\mathrm{s}$ followed by baking at $180{ }^{\circ} \mathrm{C}$ for $30 \mathrm{~min}$ under air. The optimized concentration of polymers was $18 \mathrm{mg} / \mathrm{mL}$ in $1: 1$ mixture of chloroform and TCE. The solutions were prepared inside a glovebox and stirred at $40{ }^{\circ} \mathrm{C}$ for $3 \mathrm{~h}$ to ensure complete dissolution. Then, the polymers were spin-coated onto PEDOT:PSS-coated ITO substrates at $1000 \mathrm{rpm}$ for $60 \mathrm{~s}$ with an acceleration of $500 \mathrm{rpm} / \mathrm{s}$. Finally, $100 \mathrm{~nm} \mathrm{Ag}$ was evaporated onto the polymer-coated substrates at the rate of 1 $\AA /$ s by using a shadow mask, defining the active pixel area of $4.5 \mathrm{~mm}^{2}$, in a thermal evaporator at a pressure of $<2 \times 10^{-6}$ Torr.

The room temperature dielectric measurements were performed in a closed cycle $\mathrm{He}$ cryostat (Cryo Industries Inc.) by using a Keysight E4990A impedance analyzer. Silver contacts were made on the thin films (in the device), one on the ITO substrate and another on the deposited Ag film to make it into a capacitive circuit. The pixel area of $4.5 \mathrm{~mm}^{2}$ is considered here as the active area common between the two electrodes. Several such pixel areas were selected for the experiment to obtain a better estimate of the dielectric constant. The measurements were performed in the frequency range of $100 \mathrm{~Hz}-10 \mathrm{MHz}$ at $\mathrm{RT}$ with an $\mathrm{AC}$ drive voltage of $0.5 \mathrm{~V}$ in the presence of stray light and in the dark condition to nullify the effect of light-induced exciton formation. The measurements were also done in the DC bias of -0.5 and -1.0 $\mathrm{V}$ in the dark to cease the effect of electronic charges on the film.

A broadband pump-probe femtosecond TA spectrometer Helios (Spectra-Physics, Newport Corp.) was used to measure the TAS spectra and kinetics for thin film samples. The measurements were performed following earlier reported protocols. $^{53}$ Photothermal deflection spectroscopy (PDS) was performed following a procedure reported earlier. ${ }^{54}$

Grazing-incidence wide-angle X-ray scattering (GIWAXS) measurements were collected at the small- and wide-angle $\mathrm{X}$ ray scattering beamline at the Australian Synchrotron. ${ }^{55}$ The detector utilized was a Pilatus $1 \mathrm{M}$ active pixel $2 \mathrm{D}$ detector with $0.172 \mathrm{~mm} \times 0.172 \mathrm{~mm}$ pixels, in integration mode, positioned $\sim 400 \mathrm{~mm}$ from the sample location. The precise sample-todetector distance was determined with a silver behenate 
Table 1. Dielectric Constant, Optical Bandgap, and Electrochemical Bandgap of Polymers as Determined by Impedance Spectroscopy, UV-Vis Spectroscopy, and Cyclic Voltammetry, Respectively

\begin{tabular}{|c|c|c|c|c|c|}
\hline polymers & $\varepsilon_{\mathrm{r}}^{a}$ & optical bandgap $^{b}(\mathrm{eV})$ & electrochemical bandgap ${ }^{c}(\mathrm{eV})$ & $\operatorname{HOMO}^{c}(\mathrm{eV})$ & $\operatorname{LUMO}^{c}(\mathrm{eV})$ \\
\hline BBT-3TEG-TDPP & $5.16(5.09 \pm 0.04)$ & 1.46 & 1.59 & -5.20 & -3.61 \\
\hline $\mathrm{P}(\mathrm{gNDI}-\mathrm{TDPP})$ & $5.15(5.14 \pm 0.01)$ & 1.35 & 1.20 & -5.35 & -4.15 \\
\hline TDPP-3TEG-TDPP & $3.56(3.31 \pm 0.18)$ & 1.24 & 1.15 & -5.03 & -3.88 \\
\hline 2DPP-OD-TEG & $4.44(4.42 \pm 0.01)$ & 1.18 & 1.61 & -5.34 & -3.73 \\
\hline
\end{tabular}

${ }^{a}$ Dielectric constant at $0.1 \mathrm{MHz}$ in the dark. ${ }^{b}$ Extracted from the absorption onsets of polymer thin films. ${ }^{c}$ Extracted from CV.

standard. We used $15 \mathrm{keV}$ incident $\mathrm{X}$-rays focused to approximately a $0.25 \mathrm{~mm} \times 0.1 \mathrm{~mm}$ spot to provide a large enough $q$-space. An angle of incidence close to the critical angle was used, chosen as the angle that maximized the scattering intensity. The $2 \mathrm{D}$ raw data were reduced and analyzed with a modified version of Nika. ${ }^{56}$

\section{RESULTS AND DISCUSSION}

The polymers were synthesized via Stille and Suzuki coupling reactions. The synthetic routes for the polymers BBT-3TEGTDPP, TDPP-3TEG-TDPP, and P(gNDI-TDPP) are shown in Scheme 1. The required four monomers 3TEGTDPP- $\mathrm{Br}_{2}$, $\mathrm{BBT}\left(\mathrm{SnBu}_{3}\right)_{2}, \mathrm{TDPP}(\mathrm{BE})_{2}$ and NDITEG-Br${ }_{2}$ were synthesized according to the literature reported procedures. ${ }^{51,52}$ The polymer BBT-3TEG-TDPP was obtained with Stille coupling of BBT $\left(\mathrm{SnBu}_{3}\right)_{2}$ and TDPP-3TEG-TDPP by using $\mathrm{Pd}\left(\mathrm{PPh}_{3}\right)_{4}$ as a catalyst, whereas polymers TDPP-3TEG-TDPP and $\mathrm{P}$ (gNDI-TDPP) were synthesized via Suzuki coupling reaction by using $\mathrm{Pd}_{2}(\mathrm{dba})_{3}$ as the catalyst. The detailed procedures for the synthesis of polymers are described in the Supporting Information. All four precursors were purified by silica gel chromatography; structures and purity were verified by ${ }^{1} \mathrm{H}$ NMR and ${ }^{13} \mathrm{C}$ NMR. The final polymers were purified by Soxhlet extraction and characterized with GPC. The molecular weights of the polymers are determined by using GPC and are tabulated in Table S1. All the polymers have polydispersity indices (PDI) between 2 and 4. The TGA studies revealed up to $95 \%$ weight retention of all the polymers until $240{ }^{\circ} \mathrm{C}$ (Figure S8), depicting their thermal stability.

The molecular design is focused on coupling TDPP with TDPP substituted with alkyl or TEG side-chains (2DPP-ODTEG and TDPP-3TEG-TDPP). We also coupled TDPP with BDT (BBT-3TEG-TDPP) and NDI (P(gNDI-TDPP)) units with different side-chains. To understand the effect of multiple TEG chains on optical and dielectric properties, without hindering molecular packing, a phenyl group substituted with three TEG chains was incorporated in the TDPP moiety with a triazole spacer. TDPP-3TEG-TDPP and 2DPP-OD-TEG have a similar molecular backbone of TDPP-TDPP but with different side-chains, whereas TDPP-3TEG-TDPP and BBT3TEG-TDPP have similar side-chains but BBT-3TEG-TDPP has varied strength of the $\mathrm{D}-\mathrm{A}$ conjugated backbone. In addition, copolymer $\mathrm{P}$ (gNDI-TDPP) was synthesized with a polar side-chains having ester functionality attached to the nitrogen of the NDI group. The polymers substituted with polar side-chains were found to be highly soluble in solvents like chloroform, chlorobenzene, and TCE. The presence of unsymmetrical side-chains in TDPP-3TEG-TDPP and BBT3TEG-TDPP enhanced their solubility as compared to 2DPPOD-TEG. The molecular structures of the copolymers are shown in Figure 2a.

Figures $2 \mathrm{~b}$ and $2 \mathrm{c}$ illustrate the optical absorption spectra of the polymers collected in solution and thin film. In solution, we observed a typical feature of donor-acceptor copolymers. The prominent peaks at higher wavelengths correspond to the lowest lying delocalized $\pi-\pi^{*}$ transitions with a prominent signature of intramolecular charge transfer (ICT). In addition, multiple peaks with low oscillator strength were observed below $500 \mathrm{~nm}$, which are attributed to higher energy $\pi-\pi^{*}$ transitions. The nature of the absorption spectra appeared similar for TDPP-3TEG-TDPP and 2DPP-OD-TEG, whereas an apparent blue-shift was observed for BBT-3TEG-TDPP and $\mathrm{P}$ (gNDI-TDPP). The extent of the blue-shift and oscillator strength was found to be dependent on the nature of polymer molecular structure. This implies that the intramolecular electronic coupling within the polymer structure is strongly influenced by the strength of donor and acceptor. In thin films, red-shifts were clearly observed for ICT and $\pi-\pi^{*}$ transition peaks, suggesting the enhancement of $\pi-\pi$ stacking and planarization of polymer chains in the solid state. The apparent red-shift in absorption and the change in vibronic peak ratio are the characteristics of polymer aggregates and highlight the importance of internal electronic structure. Here, we have not investigated in detail the role of coherent coupling mechanism with the theoretical framework put forward by Spano et al. ${ }^{57,58}$ To experimentally determine energetic disorder of all the polymers, we performed PDS to quantitatively estimate the $E_{\mathrm{U}}$ (Figure $2 \mathrm{~d}$ ). The lower the $E_{\mathrm{U}}$, the less the energetic disorder or defect states in the material, and hence this results in a major contributing factor in reducing the voltage loss in a photovoltaic cell.

To determine the highest occupied molecular orbitals (HOMO) and lowest unoccupied molecular orbitals (LUMO) of the polymers, CV was performed. Ferrocene was used as the standard, and the $E_{\mathrm{HOMO}}$ was calculated by using the formula $E_{\text {Hомо }}=4.8 \mathrm{eV}+\Delta E$, where $\Delta E$ is calculated by measuring the difference between the onset of oxidation and the half-wave potential of the ferrocene standard. Similarly, $E_{\mathrm{LUMO}}=4.8 \mathrm{eV}-\Delta E$, where $\Delta E$ is calculated by measuring the difference between the onset of reduction and the half-wave potential of the ferrocene standard. ${ }^{59}$ The cyclic voltammograms of all the polymers along with that of ferrocene standard are shown in Figure S5a-d. BBT-3TEGTDPP, P(gNDI-TDPP), and 2DPP-OD-TEG show one-step oxidation and reduction reversibly. TDPP-3TEG-TDPP exhibits two-step reduction and oxidation due to high electron affinity of DPP core, stabilizing the reduced form of the polymer backbone. Figure S5e shows the HOMO/LUMO levels of all the polymers. All being medium- to low-bandgap polymers with deep-lying LUMO levels and wide absorption show that these can potentially be applied in organic photovoltaics (OPV). The optical and electrochemical bandgaps of the polymers along with their HOMO/LUMO levels as extracted from CV are shown in Table 1.

The dielectric constants of all the polymers were accurately measured by using impedance spectroscopy following the 


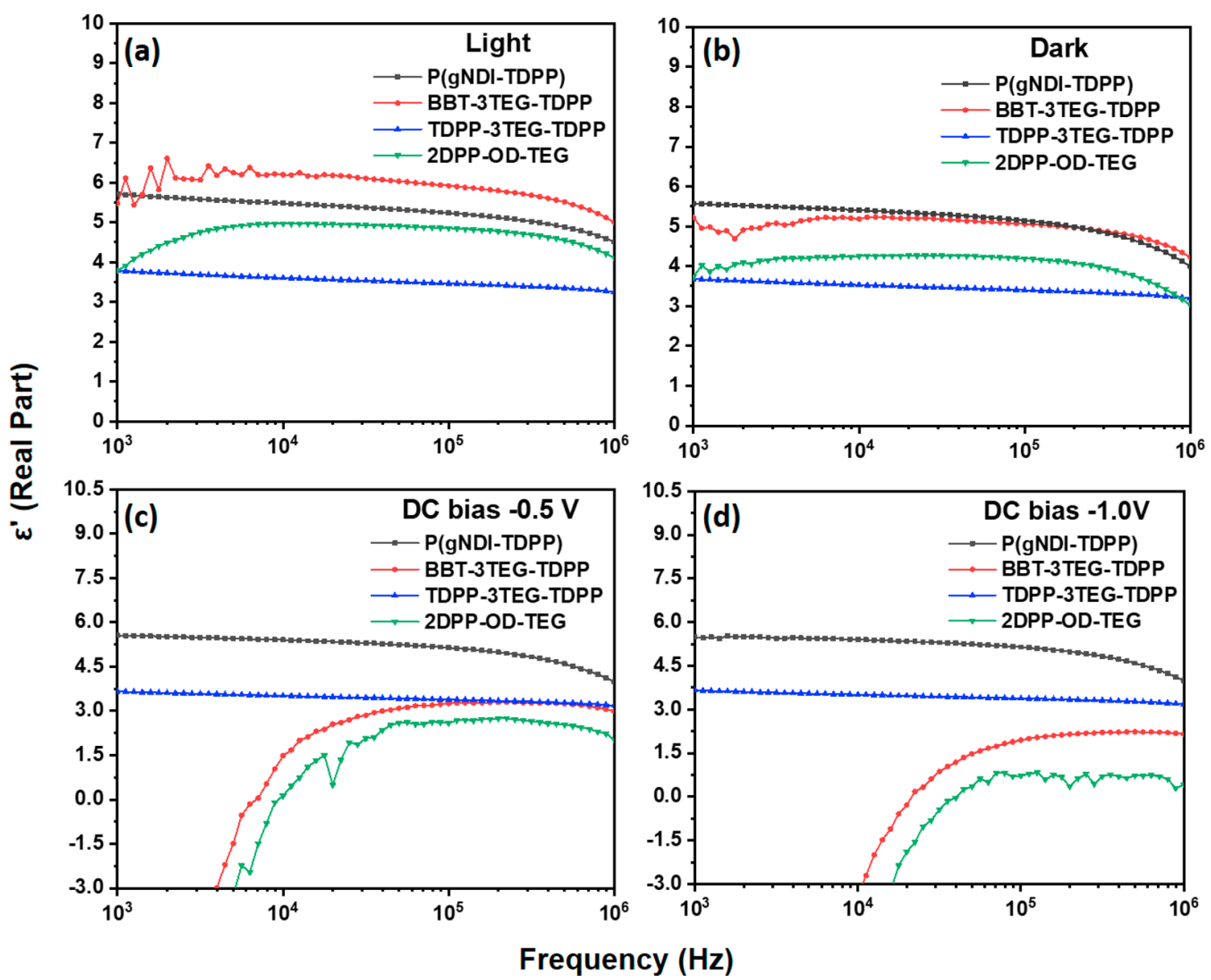

Figure 3. Relative dielectric constants of four polymers measured by using impedance spectroscopy in (a) stray light, (b) the dark, and under a DC bias of $(\mathrm{c})-0.5 \mathrm{~V}$ and $(\mathrm{d})-1.0 \mathrm{~V}$. The measurements were performed at room temperature with an AC drive voltage of $0.5 \mathrm{~V}$.
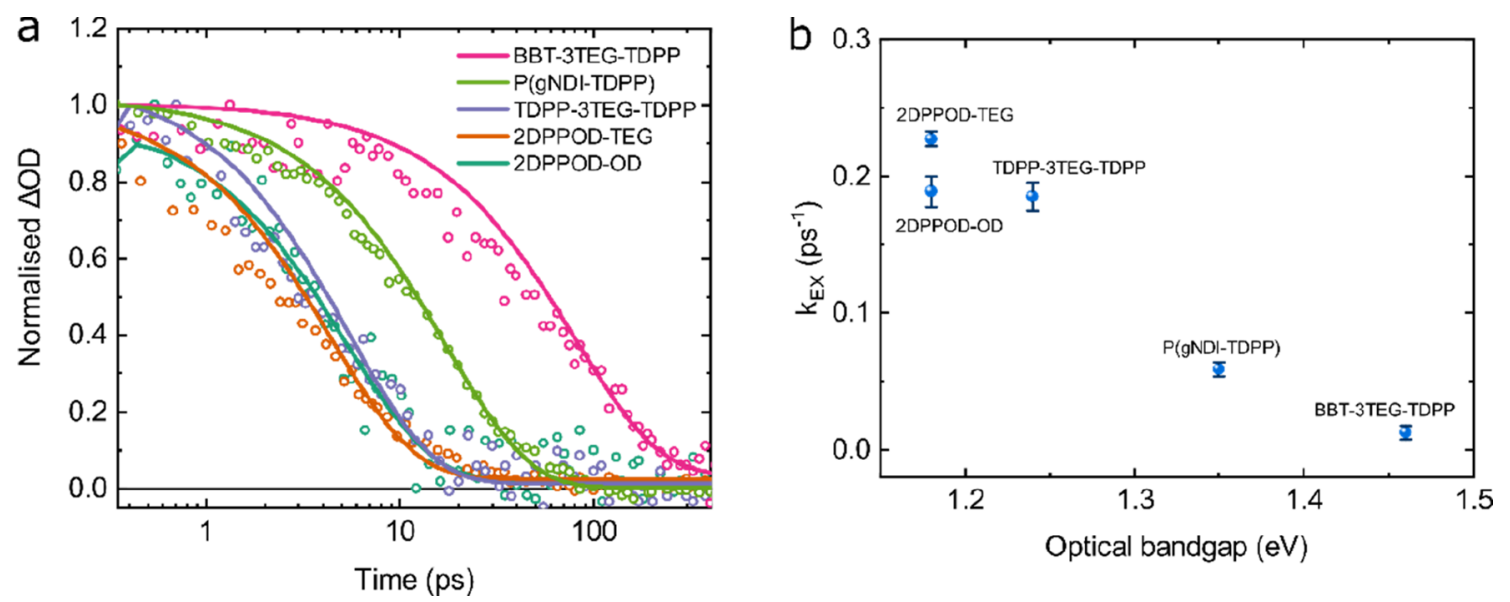

Figure 4. (a) Normalized transient absorption kinetics for the studied materials. (b) Plot of exciton decay rate $\left(k_{\mathrm{EX}}\right)$ against the bandgap of the studied materials. Samples were excited at $700 \mathrm{~nm}$ and kept under $\mathrm{N}_{2}$ during measurements.

protocols laid by Hughes et al. ${ }^{36}$ The detailed method of sample preparation and measurement is given in the Supporting Information. Precise care was taken not to overestimate the $\varepsilon_{\mathrm{r}}$ of the polymers. Table 1 summarizes the $\varepsilon_{\mathrm{r}}$ values of all the polymers at $1 \mathrm{MHz}$ measured at room temperature in the absence of light. BBT-3TEG-TDPP shows highest $\varepsilon_{\mathrm{r}}$ among all followed by P(gNDI-TDPP). 2DPP-ODTEG shows similar $\varepsilon_{\mathrm{r}}$ values as reported in the literature before. ${ }^{33}$ TDPP-3TEG-TDPP shows the lowest value among the series which can be attributed to its minimal backbone polarization. The $\varepsilon_{\mathrm{r}}$ values of the polymers remained almost constant throughout the sweeping frequency range until 1 $\mathrm{MHz}$ (Figure $3 \mathrm{a}-\mathrm{d}$ ). The role of a TEG chain in providing high dipolar polarization because of its tendency to reorient even in higher frequencies is well established. ${ }^{33}$ The values of $\varepsilon_{\mathrm{r}}$ are marginally lower in dark as compared to that in ambient light which is expected from these low-bandgap semiconducting polymers (Figure 3a,b). The devices were reversely biased 

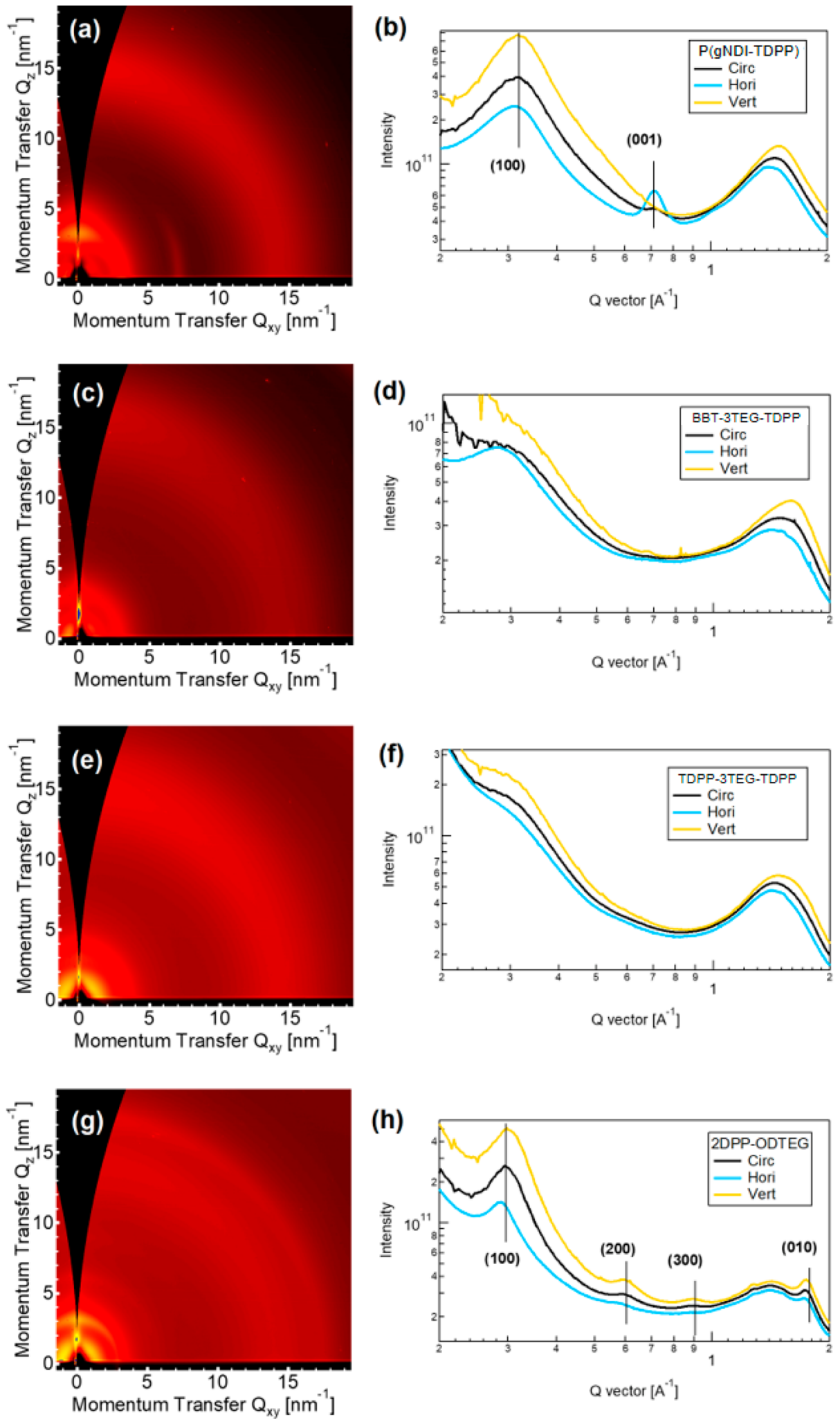

Figure 5. (a, c, e, g) 2D GIWAXS patterns and $1 \mathrm{D}$ line profiles (b, d, f, h) taken of P(gNDI-TDPP) (a, b), BBT-3TEG-TDPP (c, d), TDPP-3TEGTDPP (e, f), and 2DPP-OD-TEG (g, h).

by using DC to completely deplete the active layer of any charge carriers (Figure 3c,d), which was confirmed from the capacitance response converging into the geometrical value $\left(C_{\mathrm{g}}\right.$ $\left.=\varepsilon_{0} \varepsilon_{\mathrm{r}} / d\right)$ (Figure $S 6$ ). Frequency-independent capacitance values were observed for all the polymers signifying the depletion of all charge carriers from the device. The drop in dielectric constant values for all the polymers under DC bias was significant, barring $\mathrm{P}$ (gNDI-TDPP) which shows minimal drop. The role of side-chain could be playing a very crucial role here as it is different from the ones in the other three polymers. The contribution of dipolar polarizations toward dielectric constant is evident from the Figure 3. 
To understand the exciton lifetime and diffusion length, TA spectroscopy was employed to study pristine polymer thin films. Under photoexcitation, all the polymers exhibit broad photoinduced absorption (PIA) features in the near-infrared region, assigned to photogenerated excitons as shown in Figure S7. Transient absorption kinetics of all the polymers with different fluences are shown in Figure S8. The spectral shapes stay consistent throughout the measurement time window of up to $6 \mathrm{~ns}$, indicating only excitons are present and there is no signal of charge generation. Turning to the kinetics, we fitted the transient kinetics with monoexponential decay (Figure 4a). Among these materials, BBT-3TEG-TDPP exhibits the longest lifetime of $80 \pm 3.3 \mathrm{ps}$, followed by $\mathrm{P}(\mathrm{gNDI}-\mathrm{TDPP})$ with a lifetime of $17 \pm 0.3 \mathrm{ps}$, and the rest of the polymers show lifetimes on the order of 5 ps (all measured in the low excitation density limit). By use of the previously described method, ${ }^{60}$ the diffusion length was calculated and was found to be the longest for BBT-3TEG-TDPP of $8 \mathrm{~nm}$. This diffusion length was reduced to $<4 \mathrm{~nm}$ for the rest of polymers, consistent with their shorter exciton lifetimes, and therefore limited their performance in photovoltaic devices. To elucidate if the dielectric constant affects the exciton lifetime, we compared the kinetics between two polymers with the same bandgap but dramatically different dielectric constants, 2DPPOD-TEG $\left(\varepsilon_{\mathrm{r}}=4.4\right)$ and 2DPP-OD-OD $\left(\varepsilon_{\mathrm{r}}=2.1\right) .{ }^{33}$ The chemical structure of 2DPP-OD-OD is shown in Scheme S1. We found that they have similar exciton lifetimes of $5 \mathrm{ps}$, suggesting that the dielectric constant has a negligible effect on the exciton lifetime for these polymers. However, plotting the polymer exciton decay rate against their bandgap (Figure $4 b$ ), we observe that its decay rate decreases with increasing optical bandgap, showing an approximately linear relationship between the $\ln (1 /$ lifetime) and bandgap (see Figure S9 for details), consistent with energy gap law behavior, as also reported by others. ${ }^{61,62}$

To understand the molecular packing and crystallinity of the polymers in solid state, we performed GIWAXS studies. From the 2D GIWAXS plot of all the four polymers in Figure 5, it is evident that the TDPP-3TEG-TDPP and BBT-3TEG-TDPP are weakly crystalline as indicated by the broad, diffuse diffraction rings. 2DPP-OD-TEG shows stronger lamellar stacking, labeled (100), with diffraction up to third order apparent. The lamellar stacking peak of 2DPP-OD-TEG is located at a $q$ value of $0.298 \AA^{-1}$ corresponding to a $d$-spacing of 21.1 A. At higher q, 2DPP-OD-TEG exhibits a (010) peak at a $q$ value of $1.74 \AA^{-1}$, which corresponds to a $\pi-\pi$ stacking distance of $3.61 \AA ̊ . \mathrm{P}$ (gNDI-TDPP) also exhibits semicrystallinity although it is not as ordered as 2DPP-OD-TEG. A lamellar stacking peak for $\mathrm{P}$ (gNDI-TDPP) is seen at $q=$ $0.315 \AA^{-1}$ corresponding to a $d$-spacing of $19.9 \AA$, which is a tighter lamellar stacking compared to 2DPP-OD-TEG. $\mathrm{P}$ (gNDI-TDPP) does not exhibit a distinct $\pi-\pi$ stacking peak but does show a pronounced (001) backbone reflection, suggesting a relatively rigid backbone stacking which is expected because of a more planar backbone. The backbone stacking peak is located at a $q$ value of $0.715 \AA^{-1}$, corresponding to $d$-spacing of $8.78 \AA$. However, these results could not be correlated to the observed highest exciton diffusion length of BBT-3TEG-TDPP.

\section{CONCLUSION}

In summary, we report the synthesis as well as dielectric and optical properties of a series of low-bandgap conjugated polymers. Multiple TEG side-chains were introduced to enhance the dielectric constant of these polymers. Our studies show that the combined effect of dipole moment in polymer backbone and side-chain polarization resulted in an enhanced $\varepsilon_{\mathrm{r}}$ for one of the conjugated polymers (BBT-3TEG-TDPP) in the low-frequency range. TA spectroscopy studies revealed that exciton lifetime and diffusion length are long for BBT-3TEGTDPP. This study identifies the important guideline related to molecular design such as substitution of multiple polar sidechains in conjugated polymers enhances the dielectric constant of conjugated polymers. However, it fails to surpass Coulombic attraction between the photogenerated hole and electron. As a further step, increasing the electronic polarization of the polymer backbone may improve the $\varepsilon_{\mathrm{r}}$ in higher frequencies, which may provide desirable environment to dissociate excitons, and more efforts should be made toward designing such conjugated polymers. The GIWAXS results revealed that BBT-3TEG-TDPP and TDPP-3TEG-TDPP are amorphous in nature, whereas 2DPP-OD-TEG and P(gNDI-TDPP) have semicrystalline nature. Understanding the higher exciton diffusion length in the amorphous BBT-3TEG-TDPP system would require concerted theoretical and experimental studies which is a part of our further investigation.

\section{ASSOCIATED CONTENT}

\section{Supporting Information}

The Supporting Information is available free of charge at https://pubs.acs.org/doi/10.1021/acs.jpcc.1c00340.

Synthetic procedures of polymers, molecular weight, thermogravimetric analysis, cyclic voltammograms of pristine polymers, capacitance vs frequency plots, infrared TA spectra, TA kinetics, and exciton rate vs bandgap (PDF)

\section{AUTHOR INFORMATION}

\section{Corresponding Authors}

James R. Durrant - Department of Chemistry and Centre for Processable Electronics, Imperial College London, London, U.K.; SPECIFIC, College of Engineering, Swansea University, Swansea SA1 8EN, U.K.; ○ orcid.org/0000-0001-83537345; Email: j.durrant@imperial.ac.uk

Satish Patil - Solid State and Structural Chemistry Unit, Indian Institute of Science, Bangalore 560012, India; 다이.org/0000-0003-3884-114X; Email: spatil@ iisc.ac.in

\section{Authors}

Aiswarya Abhisek Mohapatra - Solid State and Structural Chemistry Unit, Indian Institute of Science, Bangalore 560012, India; 이이.org/0000-0002-4633-7771

Yifan Dong - Department of Chemistry and Centre for Processable Electronics, Imperial College London, London, U.K.; ○ orcid.org/0000-0003-2912-3322

Puttaraju Boregowda - Solid State and Structural Chemistry Unit, Indian Institute of Science, Bangalore 560012, India

Ashutosh Mohanty - Solid State and Structural Chemistry Unit, Indian Institute of Science, Bangalore 560012, India

Aditya Sadhanala - Optoelectronics Group, Cavendish Laboratory, Cambridge CB3 OHE, U.K.; Centre for Nano Science and Engineering, Indian Institute of Science, Bangalore 560012, India; (1) orcid.org/0000-0003-28324894 
Xuechen Jiao - Department of Materials Science and Engineering, Monash University, Clayton, VIC 3800, Australia

Awadhesh Narayan - Solid State and Structural Chemistry Unit, Indian Institute of Science, Bangalore 560012, India

Christopher R. McNeill - Department of Materials Science and Engineering, Monash University, Clayton, VIC 3800,

Australia; (1) orcid.org/0000-0001-5221-878X

Complete contact information is available at:

https://pubs.acs.org/10.1021/acs.jpcc.1c00340

\section{Notes}

The authors declare no competing financial interest.

\section{ACKNOWLEDGMENTS}

A.A.M. thanks Mr. Satya Prakash Yadav for his help in conducting the $\mathrm{CV}$ measurements. A.A.M. acknowledges IISc Bangalore for a Senior Research Fellowship. S.P. acknowledge support from the EPSRC project Strategic University Network to Revolutionize Indian Solar Energy-SUNRISE (EP/ P032591/1) and the Department of Science and Technology, New Delhi, for a Swarnajayanti Fellowship and SERB, IRHPA grant. This work was performed in part at the SAXS/WAXS beamline $^{55}$ at the Australian Synchrotron, part of acknowledges support from the Indian Institute of Science start-up grant (SG/MHRD-19-0001).

\section{REFERENCES}

(1) Pope, M.; Swenberg, C. E. Electronic Processes in Organic Crystals and Polymers; Oxford University Press: 1999.

(2) Proctor, C. M.; Kuik, M.; Nguyen, T. Q. Charge Carrier Recombination in Organic Solar Cells. Prog. Polym. Sci. 2013, 38, $1941-1960$.

(3) Halls, J. J. M.; Walsh, C. A.; Greenham, N. C.; Marseglia, E. A.; Friend, R. H.; Moratti, S. C.; Holmes, A. B. Efficient Photodiodes from Interpenetrating Polymer Networks. Nature 1995, 376 (6540), 498-500.

(4) Yu, G.; Gao, J.; Hummelen, J. C.; Wudl, F.; Heeger, A. J. Polymer Photovoltaic Cells: Enhanced Efficiencies via a Network of Internal Donor-Acceptor Heterojunctions. Science (Washington, DC, U. S.) 1995, 270 (5243), 1789.

(5) Liu, Q.; Jiang, Y.; Jin, K.; Qin, J.; Xu, J.; Li, W.; Xiong, J.; Liu, J.; Xiao, Z.; Sun, K.; et al. 18\% Efficiency Organic Solar Cells. Sci. Bull. 2020, 65 (4), 272-275.

(6) Wang, T.; Kupgan, G.; Brédas, J. L. Organic Photovoltaics: Relating Chemical Structure, Local Morphology, and Electronic Properties. Trends Chem. 2020, 2, 535.

(7) Savagatrup, S.; Printz, A. D.; O’Connor, T. F.; Zaretski, A. V.; Rodriquez, D.; Sawyer, E. J.; Rajan, K. M.; Acosta, R. I.; Root, S. E.; Lipomi, D. J. Mechanical Degradation and Stability of Organic Solar Cells: Molecular and Microstructural Determinants. Energy Environ. Sci. 2015, 8, 55-80.

(8) Cheng, P.; Zhan, X. Stability of Organic Solar Cells: Challenges and Strategies. Chem. Soc. Rev. 2016, 45, 2544-2582.

(9) Liu, T.; Huo, L.; Chandrabose, S.; Chen, K.; Han, G.; Qi, F.; Meng, X.; Xie, D.; Ma, W.; Yi, Y. Optimized Fibril Network Morphology by Precise Side-Chain Engineering to Achieve HighPerformance Bulk-Heterojunction Organic Solar Cells. Adv. Mater. 2018, DOI: 10.1002 /adma.201707353.

(10) Cao, B.; Adutwum, L. A.; Oliynyk, A. O.; Luber, E. J.; Olsen, B. C.; Mar, A.; Buriak, J. M. How to Optimize Materials and Devices via Design of Experiments and Machine Learning: Demonstration Using Organic Photovoltaics. ACS Nano 2018, 12 (8), 7434-7444.

(11) Du, X.; Heumueller, T.; Gruber, W.; Classen, A.; Unruh, T.; Li, N.; Brabec, C. J. Efficient Polymer Solar Cells Based on Non-
Fullerene Acceptors with Potential Device Lifetime Approaching 10 Years. Joule 2019, 3 (1), 215-226.

(12) Baran, D.; Ashraf, R. S.; Hanifi, D. A.; Abdelsamie, M.; Gasparini, N.; Röhr, J. A.; Holliday, S.; Wadsworth, A.; Lockett, S.; Neophytou, M.; et al. Reducing the Efficiency-Stability-Cost Gap of Organic Photovoltaics with Highly Efficient and Stable Small Molecule Acceptor Ternary Solar Cells. Nat. Mater. 2017, 16 (3), 363-369.

(13) Collins, B. A.; Tumbleston, J. R.; Ade, H. Miscibility, Crystallinity, and Phase Development in P3HT/PCBM Solar Cells: Toward an Enlightened Understanding of Device Morphology and Stability. J. Phys. Chem. Lett. 2011, 2 (24), 3135-3145.

(14) Kim, M.; Lee, J.; Jo, S. B.; Sin, D. H.; Ko, H.; Lee, H.; Lee, S. G.; Cho, K. Critical Factors Governing Vertical Phase Separation in Polymer-PCBM Blend Films for Organic Solar Cells. J. Mater. Chem. A 2016, 4 (40), 15522-15535.

(15) Li, N.; Perea, J. D.; Kassar, T.; Richter, M.; Heumueller, T.; Matt, G. J.; Hou, Y.; Güldal, N. S.; Chen, H.; Chen, S.; et al. Abnormal Strong Burn-in Degradation of Highly Efficient Polymer Solar Cells Caused by Spinodal Donor-Acceptor Demixing. Nat. Commun. 2017, 8 (1), 1-9.

(16) Menke, S. M.; Ran, N. A.; Bazan, G. C.; Friend, R. H. Understanding Energy Loss in Organic Solar Cells: Toward a New Efficiency Regime. Joule 2018, 2 (1), 25-35.

(17) Benduhn, J.; Tvingstedt, K.; Piersimoni, F.; Ullbrich, S.; Fan, Y.; Tropiano, M.; McGarry, K. A.; Zeika, O.; Riede, M. K.; Douglas, C. J. Intrinsic Non-Radiative Voltage Losses in Fullerene-Based Organic Solar Cells. Nat. Energy 2017, DOI: 10.1038/nenergy.2017.53.

(18) Eisner, F. D.; Azzouzi, M.; Fei, Z.; Hou, X.; Anthopoulos, T. D.; Dennis, T. J. S.; Heeney, M.; Nelson, J. Hybridization of Local Exciton and Charge-Transfer States Reduces Nonradiative Voltage Losses in Organic Solar Cells. J. Am. Chem. Soc. 2019, 141 (15), 6362-6374.

(19) Liu, J.; Chen, S.; Qian, D.; Gautam, B.; Yang, G.; Zhao, J.; Bergqvist, J.; Zhang, F.; Ma, W.; Ade, H.; et al. Fast Charge Separation in a Non-Fullerene Organic Solar Cell with a Small Driving Force. Nat. Energy 2016, 1 (7), 1-7.

(20) Zhong, Y.; Causa', M.; Moore, G. J.; Krauspe, P.; Xiao, B.; Günther, F.; Kublitski, J.; Shivhare, R.; Benduhn, J.; BarOr, E. et al. Sub-Picosecond Charge-Transfer at near-Zero Driving Force in Polymer:Non-Fullerene Acceptor Blends and Bilayers. Nat. Commun. 2020, 11 (1). DOI: 10.1038/s41467-020-14549-w.

(21) Hood, S. N.; Kassal, I. Entropy and Disorder Enable Charge Separation in Organic Solar Cells. J. Phys. Chem. Lett. 2016, 7 (22), $4495-4500$

(22) Cho, N.; Schlenker, C. W.; Knesting, K. M.; Koelsch, P.; Yip, H. L.; Ginger, D. S.; Jen, A. K. Y. High-Dielectric Constant SideChain Polymers Show Reduced Non-Geminate Recombination in Heterojunction Solar Cells. Adv. Energy Mater. 2014, DOI: 10.1002/ aenm.201301857.

(23) Zhang, S.; Zhang, Z.; Liu, J.; Wang, L. Fullerene Adducts Bearing Cyano Moiety for Both High Dielectric Constant and Good Active Layer Morphology of Organic Photovoltaics. Adv. Funct. Mater. 2016, 26 (33), 6107-6113.

(24) Jahani, F.; Chiechi, R. C.; Hummelen, J. C. Fullerene Derivatives with Increased Dielectric Constants. Chem. Commun. 2014, 50 (73), 10645-10647.

(25) Liu, X.; Xie, B.; Duan, C.; Wang, Z.; Fan, B.; Zhang, K.; Lin, B.; Colberts, F. J. M.; Ma, W.; Janssen, R. A. J.; et al. A High Dielectric Constant Non-Fullerene Acceptor for Efficient Bulk-Heterojunction Organic Solar Cells. J. Mater. Chem. A 2018, 6 (2), 395-403.

(26) Hughes, M. P.; Rosenthal, K. D.; Dasari, R. R.; Luginbuhl, B. R.; Yurash, B.; Marder, S. R.; Nguyen, T. Q. Charge Recombination Dynamics in Organic Photovoltaic Systems with Enhanced Dielectric Constant. Adv. Funct. Mater. 2019, 29 (29). DOI: 10.1002/ adfm.201901269. 
(27) Brebels, J.; Manca, J. V.; Lutsen, L.; Vanderzande, D.; Maes, W. High Dielectric Constant Conjugated Materials for Organic Photovoltaics. J. Mater. Chem. A 2017, 5 (46), 24037-24050.

(28) Brebels, J.; Douvogianni, E.; Devisscher, D.; Thiruvallur Eachambadi, R.; Manca, J.; Lutsen, L.; Vanderzande, D.; Hummelen, J. C.; Maes, W. An Effective Strategy to Enhance the Dielectric Constant of Organic Semiconductors-CPDTTPD-Based Low Bandgap Polymers Bearing Oligo(Ethylene Glycol) Side Chains. J. Mater. Chem. C 2018, 6 (3), 500-511.

(29) Armin, A.; Stoltzfus, D. M.; Donaghey, J. E.; Clulow, A. J.; Nagiri, R. C. R.; Burn, P. L.; Gentle, I. R.; Meredith, P. Engineering Dielectric Constants in Organic Semiconductors. J. Mater. Chem. C 2017, 5 (15), 3736-3747.

(30) Sami, S.; Haase, P. A. B.; Alessandri, R.; Broer, R.; Havenith, R. W. A. Can the Dielectric Constant of Fullerene Derivatives Be Enhanced by Side-Chain Manipulation? A Predictive First-Principles Computational Study. J. Phys. Chem. A 2018, 122 (15), 3919-3926.

(31) Zhang, G.; Clarke, T. M.; Mozer, A. J. Bimolecular Recombination in a Low Bandgap Polymer:PCBM Blend Solar Cell with a High Dielectric Constant. J. Phys. Chem. C 2016, 120 (13), 7033-7043.

(32) Sami, S.; Alessandri, R.; Broer, R.; Havenith, R. W. A. How Ethylene Glycol Chains Enhance the Dielectric Constant of Organic Semiconductors: Molecular Origin and Frequency Dependence. ACS Appl. Mater. Interfaces 2020, DOI: 10.1021/acsami.0c01417.

(33) Torabi, S.; Jahani, F.; Van Severen, I.; Kanimozhi, C.; Patil, S.; Havenith, R. W. A.; Chiechi, R. C.; Lutsen, L.; Vanderzande, D. J. M.; Cleij, T. J.; et al. Strategy for Enhancing the Dielectric Constant of Organic Semiconductors without Sacrificing Charge Carrier Mobility and Solubility. Adv. Funct. Mater. 2015, 25 (1), 150-157.

(34) Chen, X.; Zhang, Z.; Ding, Z.; Liu, J.; Wang, L. Diketopyrrolopyrrole-Based Conjugated Polymers Bearing Branched Oligo(Ethylene Glycol) Side Chains for Photovoltaic Devices. Angew. Chem., Int. Ed. 2016, 55 (35), 10376-10380.

(35) Xu, B.; Yi, X.; Huang, T. Y.; Zheng, Z.; Zhang, J.; Salehi, A.; Coropceanu, V.; Ho, C. H. Y.; Marder, S. R.; Toney, M. F. Donor Conjugated Polymers with Polar Side Chain Groups: The Role of Dielectric Constant and Energetic Disorder on Photovoltaic Performance. Adv. Funct. Mater. 2018, DOI: 10.1002/adfm.201803418.

(36) Hughes, M. P.; Rosenthal, K. D.; Ran, N. A.; Seifrid, M.; Bazan, G. C.; Nguyen, T. Q. Determining the Dielectric Constants of Organic Photovoltaic Materials Using Impedance Spectroscopy. Adv. Funct. Mater. 2018, DOI: 10.1002/adfm.201801542.

(37) Breselge, M.; Van Severen, I.; Lutsen, L.; Adriaensens, P.; Manca, J.; Vanderzande, D.; Cleij, T. Comparison of the Electrical Characteristics of Four 2,5-Substituted Poly(p-Phenylene Vinylene) Derivatives with Different Side Chains. Thin Solid Films 2006, 511$512,328-332$.

(38) Lenes, M.; Kooistra, F. B.; Hummelen, J. C.; Van Severen, I.; Lutsen, L.; Vanderzande, D.; Cleij, T. J.; Blom, P. W. M. Charge Dissociation in Polymer:Fullerene Bulk Heterojunction Solar Cells with Enhanced Permittivity. J. Appl. Phys. 2008, 104 (11), 114517.

(39) Donaghey, J. E.; Armin, A.; Burn, P. L.; Meredith, P. Dielectric Constant Enhancement of Non-Fullerene Acceptors via Side-Chain Modification. Chem. Commun. 2015, 51 (74), 14115-14118.

(40) Nguyen, T. L.; Lee, T. H.; Gautam, B.; Park, S. Y.; Gundogdu, K.; Kim, J. Y.; Woo, H. Y. Single Component Organic Solar Cells Based on Oligothiophene-Fullerene Conjugate. Adv. Funct. Mater. 2017, DOI: $10.1002 /$ adfm. 201702474.

(41) Pierini, F.; Lanzi, M.; Nakielski, P.; Pawlowska, S.; Urbanek, O.; Zembrzycki, K.; Kowalewski, T. A. Single-Material Organic Solar Cells Based on Electrospun Fullerene-Grafted Polythiophene Nanofibers. Macromolecules 2017, 50 (13), 4972-4981.

(42) Lai, W.; Li, C.; Zhang, J.; Yang, F.; Colberts, F. J. M.; Guo, B.; Wang, Q. M.; Li, M.; Zhang, A.; Janssen, R. A. J.; et al. Diketopyrrolopyrrole-Based Conjugated Polymers with Perylene Bisimide Side Chains for Single-Component Organic Solar Cells. Chem. Mater. 2017, 29 (17), 7073-7077.
(43) Bu, L.; Guo, X.; Yu, B.; Qu, Y.; Xie, Z.; Yan, D.; Geng, Y.; Wang, F. Monodisperse Co-Oligomer Approach toward Nanostructured Films with Alternating Donor-Acceptor Lamellae. J. Am. Chem. Soc. 2009, 131 (37), 13242-13243.

(44) Zhang, Q.; Cirpan, A.; Russell, T. P.; Emrick, T. DonorAcceptor Poly(Thiophene-Block-Perylene Diimide) Copolymers: Synthesis and Solar Cell Fabrication. Macromolecules 2009, 42 (4), 1079-1082.

(45) Ramos, A. M.; Rispens, M. T.; Van Duren, J. K. J.; Hummelen, J. C.; Janssen, R. A. J. Photoinduced Electron Transfer and Photovoltaic Devices of a Conjugated Polymer with Pendant Fullerenes [4]. J. Am. Chem. Soc. 2001, 123, 6714-6715.

(46) He, Y.; Heumüller, T.; Lai, W.; Feng, G.; Classen, A.; Du, X.; Liu, C.; Li, W.; Li, N.; Brabec, C. J. Evidencing Excellent Thermaland Photostability for Single-Component Organic Solar Cells with Inherently Built-In Microstructure. Adv. Energy Mater. 2019, 9 (21), 1900409.

(47) Jiang, X.; Yang, J.; Karuthedath, S.; Li, J.; Lai, W.; Li, C.; Xiao, C.; Ye, L.; Ma, Z.; Tang, Z.; et al. Miscibility-Controlled Phase Separation in Double-Cable Conjugated Polymers for SingleComponent Organic Solar Cells with Efficiencies over 8\%. Angew. Chem., Int. Ed. 2020, 59 (48), 21683-21692.

(48) Kanimozhi, C.; Yaacobi-Gross, N.; Burnett, E. K.; Briseno, A. L.; Anthopoulos, T. D.; Salzner, U.; Patil, S. Use of Side-Chain for Rational Design of n-Type Diketopyrrolopyrrole-Based Conjugated Polymers: What Did We Find Out? Phys. Chem. Chem. Phys. 2014, 16 (32), 17253-17265.

(49) Senanayak, S. P.; Ashar, A. Z.; Kanimozhi, C.; Patil, S.; Narayan, K. S. Room-Temperature Bandlike Transport and Hall Effect in a High-Mobility Ambipolar Polymer. Phys. Rev. B: Condens. Matter Mater. Phys. 2015, 91 (11), 115302.

(50) Kanimozhi, C.; Yaacobi-Gross, N.; Chou, K. W.; Amassian, A.; Anthopoulos, T. D.; Patil, S. Diketopyrrolopyrrole-Diketopyrrolopyrrole-Based Conjugated Copolymer for High-Mobility Organic FieldEffect Transistors. J. Am. Chem. Soc. 2012, 134 (40), 16532-16535.

(51) Ghosh, S.; Philips, D. S.; Saeki, A.; Ajayaghosh, A. Nanosheets of an Organic Molecular Assembly from Aqueous Medium Exhibit High Solid-State Emission and Anisotropic Charge-Carrier Mobility. Adv. Mater. 2017, 29 (10), 1605408.

(52) Giovannitti, A.; Nielsen, C. B.; Sbircea, D. T.; Inal, S.; Donahue, M.; Niazi, M. R.; Hanifi, D. A.; Amassian, A.; Malliaras, G. G.; Rivnay, J. Erratum: N-Type Organic Electrochemical Transistors with Stability in Water. Nat. Commun. 2016, 7 (13066), 1-10, DOI: $10.1038 /$ Ncomms13066.

(53) Dong, Y.; Cha, H.; Zhang, J.; Pastor, E.; Tuladhar, P. S.; McCulloch, I.; Durrant, J. R.; Bakulin, A. A. The Binding Energy and Dynamics of Charge-Transfer States in Organic Photovoltaics with Low Driving Force for Charge Separation. J. Chem. Phys. 2019, DOI: $10.1063 / 1.5079285$.

(54) Mohapatra, A. A.; Shivanna, R.; Podapangi, S.; Hinderhofer, A.; Dar, M. I.; Maity, N.; Schreiber, F.; Sadhanala, A.; Friend, R. H.; Patil, S. Role of Morphology and Förster Resonance Energy Transfer in Ternary Blend Organic Solar Cells. ACS Appl. Energy Mater. 2020, 3 (12), 12025-12036.

(55) Kirby, N. M.; Mudie, S. T.; Hawley, A. M.; Cookson, D. J.; Mertens, H. D. T.; Cowieson, N.; Samardzic-Boban, V. A LowBackground-Intensity Focusing Small-Angle X-Ray Scattering Undulator Beamline. J. Appl. Crystallogr. 2013, 46 (6), 1670-1680.

(56) Ilavsky, J. Nika : Software for Two-Dimensional Data Reduction. J. Appl. Crystallogr. 2012, 45 (2), 324-328.

(57) Hestand, N. J.; Spano, F. C. Expanded Theory of H- and JMolecular Aggregates: The Effects of Vibronic Coupling and Intermolecular Charge Transfer. Chem. Rev. 2018, 118, 7069-7163.

(58) Spano, F. C. The Spectral Signatures of Frenkel Polarons in HAnd J-Aggregates. Acc. Chem. Res. 2010, 43 (3), 429-439.

(59) Yuen, J. D.; Fan, J.; Seifter, J.; Lim, B.; Hufschmid, R.; Heeger, A. J.; Wudl, F. High Performance Weak Donor-Acceptor Polymers in Thin Film Transistors: Effect of the Acceptor on Electronic 
Properties, Ambipolar Conductivity, Mobility, and Thermal Stability. J. Am. Chem. Soc. 2011, 133 (51), 20799-20807.

(60) Cha, H.; Wheeler, S.; Holliday, S.; Dimitrov, S. D.; Wadsworth, A.; Lee, H. H.; Baran, D.; McCulloch, I.; Durrant, J. R. Influence of Blend Morphology and Energetics on Charge Separation and Recombination Dynamics in Organic Solar Cells Incorporating a Nonfullerene Acceptor. Adv. Funct. Mater. 2018, 28 (3), 1704389.

(61) Englman, R.; Jortner, J. The Energy Gap Law for Radiationless Transitions in Large Molecules. Mol. Phys. 1970, 18 (2), 285-287.

(62) Dimitrov, S.; Schroeder, B.; Nielsen, C.; Bronstein, H.; Fei, Z.;

McCulloch, I.; Heeney, M.; Durrant, J. Singlet Exciton Lifetimes in Conjugated Polymer Films for Organic Solar Cells. Polymers (Basel, Switz.) 2016, 8 (1), 14. 